\title{
The 'Netflix plus model': can subscription financing improve access to medicines in low- and middle-income countries?
}

\author{
Avi Cherla ${ }^{\mathrm{a}, \mathrm{b}}$, Natasha Howard ${ }^{\mathrm{b}}$ and Elias Mossialos ${ }^{\mathrm{a}}$ (D) \\ ${ }^{a}$ Department of Health Policy, London School of Economics and Political Science, London, UK and ${ }^{b}$ Department of Global \\ Health and Development, London School of Hygiene and Tropical Medicine, London, UK \\ ${ }^{\star}$ Corresponding author. Email: e.a.mossialos@lse.ac.uk
}

(Received 10 September 2019; revised 4 February 2020; accepted 4 February 2020; first published online 3 March 2020)

\begin{abstract}
At present, pay for prescription models are insufficient at containing costs and improving access to medicines. Subscription financing through tenders, licensing fees and unrestricted or fixed volumes can benefit stakeholders across the supply chain. Pharmaceutical manufacturers can reduce the need for marketing expenses and gain certainty in revenue. This will decrease costs, improve predictability in budget expenditure for payers and remove price as a barrier of access from patients. Inherently, low- and middle-income countries lack the purchasing power to leverage price discounts through typical price arrangements. These markets can realise substantial savings for branded and generic medicines through subscription financing. Procuring of on-patent and off-patent drugs requires separate analysis for competition effects, the length of contract and encouraging innovation in the medicine pipeline. Prices of competitive on-patent medicines and orphan drugs can be reduced through increased competition and volume. Furthermore, pooling expertise and resources through joint procurement has the potential for greater savings. Incentivising research and development within the pharmaceutical industry is essential for sustaining a competitive market, preventing monopolies and improving access to expensive treatments. However, technical capacity, forecasting demand and the quality of generic medicines present limitations which necessitate government support and international partnerships. Ultimately, improving access requires progressive financing mechanisms with patients and cost containment in mind.
\end{abstract}

Key words: Financing; health policy; low- and middle-income countries; pharmaceuticals

\section{Introduction}

Universal access to essential medicines remains a contentious global health challenge for infectious and chronic diseases. At present, negotiating a successful compromise between patients, payers and manufacturers has been inadequate, requiring a financing mechanism to balance competing interests while prioritising equitable access and affordability (Atun et al., 2017). Governments and private corporations leverage substantial influence in pharmaceutical markets and policies. Proposed strategies, including compulsory licensing under the WTO-TRIPS flexibilities and restricting patient eligibility to clinical subgroups has resulted in political and corporate resistance, patient exclusion and aggressive pricing (Smith et al., 2009).

A subscription financing model for hepatitis C treatment, coined the 'Netflix model', has implications for future financing (Trusheim et al., 2018; Moon and Erickson, 2019). An analysis of limited data from Australia indicates a net benefit for stakeholders, consumers, payers and 
manufacturers (Izaret et al., 2019; Moon and Erickson, 2019). How transferable is it, particularly to low- and middle-income countries (LMICs), and can it be used to finance other treatments?

\section{The 'Netflix model'}

The global trend of subscription e-commerce has changed consumer behaviour by encouraging demand without variable cost penalties. Subscription payment services require corporations to provide an unlimited supply of goods and services, satisfying consumer demand for a prospectively determined fixed price (Chen et al., 2018).

In 2015, Australia became the first country to implement a subscription model for pharmaceuticals. The federal government negotiated an unlimited supply of hepatitis $\mathrm{C}$ medicines for a recurring licensing fee, providing universal access to treatment at no cost to patients (Moon and Erickson, 2019). As the sole purchaser, the Australian government capitalised on monopsony power in negotiations with manufacturers to obtain price discounts due to guaranteed funding for a 5-year term and the competitive pricing behaviour of firms engaging in tender offers (Fuller and Goldfield, 2016). A prospectively determined fixed cost (licensing fee) effectively eliminates financial barriers as an impediment to accessing care for patients, encouraging compliance with treatment. In January 2019, the US state of Louisiana agreed to a 5-year term with a generic subsidiary of Gilead. Exclusion criteria under the agreement have limited patient eligibility for hepatitis C medicines to Medicaid enrolees and prison inmates (Trusheim et al., 2018; Sagonowsky, 2019).

Under a subscription policy, consumers receive free medicines, are encouraged to comply because of the fixed costs to payers and can expect high treatment rates (Izaret et al., 2019). Payers are able to negotiate low costs through bulk purchasing while pharmaceutical manufacturers benefit from higher and predictable revenue, thereby eliminating the need for advertising, distribution and marketing expenses, often twice the amount spent on R\&D for new patented medicines (Gagnon and Lexchin, 2008; Izaret et al., 2019).

\section{Proposed expansion}

Subscription financing reorganises purchasing and delivery from the micro to macro policy agenda, targeting treatment initiatives at the population level (Trusheim et al., 2018). Purchasing agreements using licensing and tendering have been proposed for chronic (e.g. asthma and diabetes) and acute conditions (e.g. hepatitis $\mathrm{C}$ and tuberculosis) requiring recurring treatment, which is especially important given the prevalence of these diseases in both high and LMICs (Goldman et al., 2008). Medicines that could benefit from subscription agreements must be part of a recurring treatment regimen and have a low marginal cost of production, and these should be considered essential pre-conditions to achieve the required scale.

In the literature, advocacy for subscription financing extends to curative therapies and medical conditions requiring recurring treatment (Goldman et al., 2008; Sood et al., 2018; Izaret et al., 2019). Alternatively, diseases with regular and low treatment costs should be prioritised as suitable candidates for which subscription-based financing could prove more effective than current pay-per-prescription models. Support for financing improvements in asthma and tuberculosis medicines, and potential use in purchasing agreements for vaccinations, suggest a few potential conditions (Goldman et al., 2008). Diabetes is a particularly strong candidate.

Diabetes accounts for a significant proportion of the global burden of disease. Paired with rising obesity rates, diabetes has significant implications for China, India and the USA, which by the World Health Organization (WHO) estimates will have over 150 million diabetics by 2030 ('WHO | Country and Regional Data on Diabetes' 2011). Most diabetics can be treated with generic medicines (American Diabetes Association, 2007). In LMICs generics are frequently used to reduce health care expenditure, these offer significant savings for patients and payers in contrast 
to branded alternatives (Razmaria, 2016). Producer's utilise tiered or equity pricing using confidential agreements and rebates to reduce prices in developing markets without affecting international prices. This results to a significant difference between the list price and confidential transaction price, and avoids the practice of external reference pricing; the international benchmark of medicine prices to reduce paying higher costs than comparator countries. In a subscription model prices are dependent on an estimated population and volume. A price-per-patient or dose is not explicitly defined making this favourable to manufacturers participating in the global pharmaceutical market (Moon and Erickson, 2019).

More commonly, firms engage in launch sequencing or no launches. This is a common strategy to delay or restrict the release of medicines in markets they are unlikely to earn desired profits. Consequently, in LMICs where originator medicines are available, prices are often substantially higher than high income countries (Perez-Casas et al., 2001; Morel et al., 2011). This is due to a lack of competition resulting in LMICs purchasing higher priced branded medicines. Price competition for patented and generic medicines in LMICs has faced significant barriers. Recent findings from the Centre for Global Development indicate that generic drugs can cost between 20 and 30 times more in LMICs (Silverman et al., 2019). Future progress for price competition in LMICs would require active purchasing mechanisms and well-developed insurance systems. However, LMICs currently lack the infrastructure to achieve these and suffer from fixed prices as a result. Therefore, patented and branded medicines are largely unavailable in lowincome settings and thus account for the predominant generic markets in these countries.

Most diabetics require regular insulin treatments and accumulate significant out-of-pocket expenses over time. Generic medicines for diabetes offer an opportunity to treat patients at a greatly reduced cost (American Diabetes Association, 2007). Thus, diabetes treatments satisfy the essential criteria for subscription financing of life-long diagnosis and intensive medication regimen. Purchasing a subscription for the entire population removes the financial barrier for patient adherence, eliminating the need to prioritise cost over wellbeing. Further, user charges including coinsurance, co-payments and deductibles can be reduced through a subscription model. Health systems relying on additional revenue from user charges to finance medicines can adjust the tender offer by lowering the bid price. Therefore, user charges can be minimised and offset with lower bid prices to reduce access dependent payments.

Improving adherence contributes to societal welfare, alleviating the financial burden on the health system without the balloon effect that results from adverse treatment compliance (Goldman et al., 2008; Thomson et al., 2010). As the global prevalence of diabetes increases, a protective measure that reduces out-of-pocket expenditure on health care can be used to finance cooperative payment models for patients, payers and manufacturers.

\section{On-patent and off-patent pharmaceutical markets}

Negotiating a subscription financing agreement requires careful consideration for anti-competitive supply-side behaviour. This poses implications for future competition, pricing and access, and will depend on the type of medicines being procured, on-patent originator brands or off-patent generics.

\subsection{Off-patent markets}

Within the off-patent pharmaceutical market generic medicines provide opportunities for cost savings. Generics are bioequivalent to branded medicines, identical in quality and active ingredients at less than $85 \%$ of the cost (Razmaria, 2016). Globally generic medicines account for the majority of pharmaceutical volume, and the predominant share of spending in LMICs. LMICs including India, China and Brazil are projected to have the greatest global increase in volume of medicines through 2020 benefiting from increased R\&D and usage (Aitken and Kleinrock, 
2015). Generic competition is characterised by many suppliers producing at or below the marginal cost of production. Producers compete based on price through a competitive bidding model to gain higher market share. Competition for generics in the off-patent market is different from branded medicines in the on-patent market and requires different consideration for financing mechanisms.

Unlike on-patent medicines, tenders in the off-patent market benefit from significant competition with multiple generic producers. Tenders for generics in the out-patient pharmaceutical markets in the Netherlands and Germany have achieved price reductions of greater than $90 \%$ (Dranitsaris et al., 2017). Awarding a tender to a single producer with many competitors can reduce the price discount achieved through competition. A split tender would prove more beneficial for sustained competition and reduced prices in markets with high volumes of substitutable generics. Segmenting the tender between a few producers; for example, three per therapeutic category, avoids price collusion and oligopolistic behaviour. If producers fail to agree on a price, bids from producers outside the therapeutic category can be requested to meet the projected demand. Under generic competition purchasers can select to extend the tender for long-term agreements but should remain aware of future innovations in treatment through health technology assessment (HTA) horizon scanning.

\subsection{On-patent markets}

Originator, branded medicines profit from monopoly power and market exclusivity as a result of patents and intellectual property rights conferred under the WTO-TRIPS agreement (Smith et al., 2009). This enables firms to charge higher prices and recover expenses incurred through R\&D. Originator medicines are protected through the principal patent term of 20 years, in addition to data exclusivity agreements and additional patent extensions which increase the duration (Smith et al., 2009). In a tender model a single firm is selected to supply the entire market for the contract. A market with a sole producer has minimal incentives to innovate, reduce prices or improve the value added. In turn, this would reduce $\mathrm{R} \& \mathrm{D}$ from competing suppliers as they would be prevented from market authorisation, leading to inefficiency in price and access. Therefore, a long-term subscription for procuring patented medicines would result in anti-competitive behaviour, a benefit to monopoly producers through elimination of future competition.

Avoiding supplier monopolies in a subscription model requires short-term agreements with greater stability for purchasers. A contract length of 3-5 years provides stable revenue for suppliers, budgetary predictability and forecasting for purchasers. Revenue and market share have shown to decrease significantly following competition (Moon and Erickson, 2019). A short-term agreement can encourage innovation and future entry from competitors, reducing the potential for a monopoly within the indication. The length of contracts can be further amended, inclusive of future innovation within the pharmaceutical pipeline and integrated alongside horizon scanning performed by HTA agencies. R\&D within the pharmaceutical sector is conducive to a competitive market. Horizon scanning through HTA agencies enables flexible contract lengths based on predicted future developments. Forecasting medicine approval can promote competition among suppliers and reduce the monopoly price paid by consumers. Purchasers can benefit from shorter agreements to reflect the anticipated timeline of future medicines entering the market.

Sustainable long-term competition achieved through $\mathrm{R} \& \mathrm{D}$ requires short tender contracts which encourage innovator market entry, and ultimately reduce the price for payers and consumers.

\section{Netflix plus}

The 'Netflix model' of subscription financing can reduce the price of first-in-class patented medicines and generics. If successful, incentivising competition and innovation through short-term contracts will produce multiple on-patent therapeutic alternatives. This can further reduce the 
price for purchasers. In turn, this will lead to a competitive environment for branded and patented medicines similar to off-patent markets, consisting of multiple producers within a therapeutic category. Split tenders and bulk contracting for on-patent medicines can facilitate competition among therapeutic alternatives and reduce the ability of suppliers to charge monopoly prices. In effect, this would create an oligopoly market for patented medicines, with producers competing to reduce prices and increase the value for consumers.

A further application of the model can be used for the treatment of rare diseases. Orphan drugs are medicines for an extremely small patient population. The United States Food and Drug Administration (FDA) defines an orphan disease as affecting less than 200,000 people, similarly the European Medicines Agency (EMA) defines it as no more than 5 in 10,000 (European Medicines Agency, 2013; US Food and Drug Administration, 2017). Orphan drugs are often granted market exclusivity and able to benefit from high prices. Negotiations and price reductions are limited with few eligible patients.

The Netflix subscription model would likely limit participation from orphan drug manufacturers. Orphan drugs are often the sole treatment option. A fee-for-service design using a pricevolume agreement, price reductions for successive purchases alongside tiered pricing in LMICs can increase affordability in select markets. For greater benefit, joint purchasing between countries through regional agreements can increase access at lower costs. Price discounts would be achieved through higher volumes, with additional savings including clawbacks, rebates and discounts as the volume increases. This requires coordination between regulators, manufacturers and payers of participating countries to determine an equitable compromise.

\section{Netflix vs Netflix plus}

Under the current Netflix agreement used by multiple states in the USA and the Australian government, a single medicine and manufacturer is awarded the tender for the specified contract length. As previously mentioned, this presents a challenge by eliminating future competition from market entrants. Conversely, the proposed Netflix plus model would incentivise R\&D and competition through a series of multiple tenders with patented therapeutic alternatives, creating an environment for patented medicines similar to the off-patent generic market. Previously, the winner of the tender would be rewarded while other manufacturers would be unable to market their product and raise revenue. In the Netflix plus amendment multiple short-term tenders will incentivise future market entrants while negotiating reduced prices, bypassing the typical exclusivity length. This is especially relevant for orphan diseases for niche indications which are often dominated by single manufacturers. In this context, when a product is launched a guaranteed source of revenue (similar to a pull-mechanism for financing) will incentivise future development. This would replicate the current effects of the off-patent medicine market for patented medicines.

Rare diseases and orphan drugs are akin to monopolistic pricing with markets limited to few or no competitors. Based off the strategy from the Netflix model a new treatment for a rare disease would limit the award of a tender to a single manufacturer, dis-incentivising innovation and competition. The proposed Netflix plus model would utilise a fee-for-service payment combined with a price-volume agreement, larger supplies of purchased medicines would proportionally reduce the cost of procurement for the payer. Purchasing agreements for orphan drugs through the Netflix plus model would encourage joint procurement from multiple countries or regional trade partnerships due to the relatively small burden of disease for each country. This would also include caveats for equity pricing which lower the cost of medicines in LMICs. Using rebates and discounts to achieve reductions in orphan drug prices would require participation from public and private stakeholders but has the potential to encourage innovation while stimulating competition, through guaranteed purchasing agreements and reduced medicine prices. 


\section{Joint procurement of medicines}

Tenders and pricing agreements for medicines have proven difficult to negotiate in LMICs. Payers face constraints in implementation with a lack of infrastructure, information technology, administration, data and expertise (WHO, 2007). Purchasers have minimal leverage to negotiate price reductions (Espin et al., 2016). Overcoming barriers requires political investment to support international collaboratives, regional blocs and joint procurement agreements to leverage price subsidies. High-income countries benefit in negotiations from economies of scale with large populations (WHO, 2007). In contrast, many LMICs have significantly sized populations but have been unable to achieve similar discounts to high income countries. Small and low-income countries have the most to benefit from joint procurement. These can be used to minimise the adverse effect of intellectual property rights on LMICs (Espin et al., 2016).

Joint procurement of pharmaceuticals has demonstrated effectiveness for advance purchasing and cross-border threats, specifically in Europe and South America (Azzopardi-Muscat et al., 2017). Regional collaboratives in both high- and low-income countries have achieved promising results; incentivising pharmaceutical competition and decreasing prices. Participating countries pay the same price regardless of population, market size or development (Azzopardi-Muscat et al., 2017). In turn, this may reduce the ability of firms to leverage differential prices across markets, through equity or Ramsey pricing.

Opportunities for purchasers to increase value and savings with subscription financing are significant (Table 1). Two notable examples include the Strategic Fund of the Pan American Health Organization (PAHO); WHO Regional Office of the Americas and the European Union (EU) Joint Procurement of medical countermeasures (Box 1).

\subsection{Joint procurement under subscription financing}

The PAHO Strategic Fund and EU Joint Procurement initiatives use tenders to acquire medicines or vaccines and achieve significant price reductions. Both agreements look to improve efficiency in purchasing through leveraging economies of scale, larger population sizes and lower transaction costs (WHO, 2007; Espin et al., 2016). The added benefit from purchasing using a subscription model enables several improvements. Patients are encouraged to comply with treatment regimens and no longer deterred from out-of-pocket user charges for accessing care. Payers benefit from significant price reductions, and patients gain access to patented and expensive medicines frequently unavailable in low-income countries. International collaboratives could minimise administrative constraints on individual member states as resources, expertise and data can be pooled across countries. Additionally, use of patent pooling can reduce the consequence of intellectual property rights and increase access to patented medicines in LMICs (WHO, 2007; Smith et al., 2009).

Notable barriers to joint procurement include absence of centralised purchasing authorities, low government involvement in health care and weak infrastructure and stakeholder relations to negotiate equitable financing agreements. International partnerships are often resource intensive and require common objectives among member states.

\section{High-income vs low-income countries}

Many countries do not cover the full cost of pharmaceutical care within universal health coverage. This necessitates co-payments, deductibles and out-of-pocket expenditures that can result in catastrophic and impoverishing outcomes for patients (Zhang et al., 2017; Nikoloski and Mossialos, 2018). Implementing a national purchasing strategy for medicines reduces the financial burden on individuals. Conservative, partial or failed adherence with treatment due to financial constraints, including pill rationing and dose splitting, has consistently resulted in negative health 
Table 1. International joint procurement strategies for medicines

\begin{tabular}{|c|c|c|c|c|c|c|}
\hline Agreement & $\begin{array}{l}\text { Countries } \\
\text { (Region) }\end{array}$ & Population & Features & $\begin{array}{l}\text { Subscription financing } \\
\text { ('Netflix') }\end{array}$ & Netflix Plus & $\begin{array}{l}\text { Monitoring and } \\
\text { Evaluation }\end{array}$ \\
\hline PAHO Strategic Fund & $\begin{array}{c}33 \\
\text { (South } \\
\text { America) }\end{array}$ & $500 \mathrm{~m}$ & $\begin{array}{l}\text { - } 150+\text { products, USD } \\
81.9 \mathrm{~m} \text { in value } \\
\text { - } 13 \mathrm{~m} \text { in savings over } \\
\text { local procurement } \\
\text { - Support from regional } \\
\text { WHO centres } \\
\text { - Partnered with USAID } \\
\text { and the Global Fund } \\
\text { for forecasting and } \\
\text { information systems } \\
\text { - Open tenders to } \\
\text { promote generic } \\
\text { competition }\end{array}$ & $\begin{array}{l}\text { - Predetermined costs } \\
\text { increase budget } \\
\text { predictability } \\
\text { - Unrestricted supply } \\
\text { reduces the need for } \\
\text { rationing and limit for } \\
\text { patient subgroups } \\
\text { - Reduces price, } \\
\text { administrative and } \\
\text { marketing expenses } \\
\text { - Can be used to reduce } \\
\text { user charges } \\
\text { - Applicable for a wide } \\
\text { range of medicines and } \\
\text { technology }\end{array}$ & $\begin{array}{l}\text { - Multiple subscriptions of } \\
\text { patented medicines } \\
\text { - Reduces price of multiple } \\
\text { therapeutic on-patent medicines } \\
\text { - Fee-for-service price scheme for } \\
\text { orphan drugs utilising } \\
\text { price-volume agreements and } \\
\text { tiered pricing } \\
\text { - Multiple countries benefit from } \\
\text { joint procurement of orphan } \\
\text { drugs through price discounts } \\
\text { from bulk purchases and } \\
\text { price-volume discounts } \\
\text { - Effective for procuring on-patent } \\
\text { medicines and orphan drugs }\end{array}$ & $\begin{array}{l}\text { - Iterative } \\
\text { multicomponent } \\
\text { strategy; } \\
\text { - Public (ministries of } \\
\text { health) and private } \\
\text { (manufacturers) } \\
\text { stakeholder interviews } \\
\text { - Analysis of tender } \\
\text { submissions } \\
\text { - Tracking patient } \\
\text { utilisation of medicines }\end{array}$ \\
\hline $\begin{array}{l}\text { EU Joint Procurement } \\
\text { of medical } \\
\text { countermeasures }\end{array}$ & $\begin{array}{l}24 \\
\text { (Europe) }\end{array}$ & $447.8 \mathrm{~m}$ & $\begin{array}{l}\text { - Voluntary, minimum } \\
\text { four countries } \\
\text { - Advance purchasing } \\
\text { - Interest for pandemic } \\
\text { influenza and BCG } \\
\text { vaccines }\end{array}$ & $\begin{array}{l}\text { - LMICs and small } \\
\text { countries benefit from } \\
\text { economies of scale in } \\
\text { purchasing } \\
\text { - Effective for procuring } \\
\text { on-patent first-in-class } \\
\text { and generic medicines }\end{array}$ & $\begin{array}{l}\text { - Stimulates competition for } \\
\text { medicines in the patented } \\
\text { market similar to the off patent } \\
\text { market }\end{array}$ & \\
\hline $\begin{array}{l}\text { Gulf Cooperation } \\
\text { Council (GCC) }\end{array}$ & $\begin{array}{l}6 \\
\text { (Middle } \\
\text { East) }\end{array}$ & $54 \mathrm{~m}$ & $\begin{array}{l}\text { - } 9000+\text { products, USD } \\
680 \mathrm{~m} \text { in value } \\
\text { - Purchasing for some } \\
\text { public sector hospitals } \\
\text { in Saudi Arabia } \\
\text { - Encourages registered } \\
\text { generic producers }\end{array}$ & & & \\
\hline $\begin{array}{l}\text { Organization of } \\
\text { Eastern Caribbean } \\
\text { States (OECS) }\end{array}$ & $\begin{array}{c}9 \\
\text { (Caribbean) }\end{array}$ & 615,000 & $\begin{array}{l}\text { - } 700 \text { portfolio items, } \\
70 \% \text { are medicines } \\
\text { - } 13 \% \text { administrative fee } \\
\text { for member states } \\
\text { - Average savings of } \\
37 \% \text { over } 5 \text { years }\end{array}$ & & & \\
\hline
\end{tabular}


Box 1. Regional case studies on joint procurement

\section{Pan American Health Organization}

PAHOs Strategic Fund coordinates pooled procurement, supply management and acquisition of strategic public health supplies and high-cost medicines (WHO, 2007; PAHO, 2015; Pan American Health Organization, 2017). Current members include 17 ministries of health and partnerships with international organisations such as the Global Fund and USAID. In 2015, negotiations led by the Strategic Fund with the MERCOSUR Latin American countries purchased an antiretroviral for the treatment of HIV/AIDS. The negotiation produced 20 million in savings, reducing the price more than $50 \%$ below the lowest available price to any participating country (USD $\$ 2.98$ to 1.27) (PAHO, 2015). In addition, negotiations with Gilead Sciences for sofosbuvir, a direct-acting antiviral for the treatment of hepatitis $C$ reduced prices to the lowest price of the country in the region (USD $\$ 81.85$ per tablet), a high cost despite pooled funding (PAHO, 2015). The Strategic Fund has increased access to several essential medicines at a significantly reduced cost with future negotiations including high-cost medicines for oncology.

\section{European Union}

The EU Joint Procurement of medical countermeasures was developed after the H1N1 influenza. This led to competition for medical supplies which caused drastic price increases across Europe (Espin et al., 2016). The joint procurement agreement was created to improve access to medicines, vaccines, antivirals and other medical equipment necessary for resolving cross-border emergencies. The European Commission is the Secretariat and responsible for coordination and logistics. Specific technical committees are established for each joint procurement plan to assess price and resource allocation. Successful procurement of the Botulinum anti-toxin in 2016 has led 19 member states to explore the opportunity for the advance purchase of pandemic influenza vaccines (Philipp, 2017).

outcomes. These challenges occur in high- and low-income countries alike, as financing challenges extend beyond regional borders. Health care system payers, e.g. insurance funds, governments and regional purchasing organisations, stress the need for greater predictability in financing to reduce budgetary shocks and provide greater certainty in resource allocation (Chen et al., 2018; Izaret et al., 2019). Negotiating a prospective fixed cost allows payers and manufacturers to achieve certainty in expenditure and revenue.

To increase transferability across countries and health systems, demographic, health system financing and cultural norm adjustments may be required to facilitate global adoption. Tailoring the model to local contexts and health systems will increase the likelihood of adoption and reduce potential opposition. Adjustments may include the use of minimal co-payments and limiting inclusion to defined patient groups to reduce payers' financial burden.

\section{Monitoring and evaluation}

Empirical evidence on the effectiveness of the Netflix model for financing medicines is not available as the earliest agreement, by the Australian government in 2015, is still under its original term. Collecting data for financing, competition and utilisation is of interest to stakeholders. Therefore, a series of recommendations for monitoring would help disseminate information and provide a prospective plan for evaluation.

Iterative monitoring and evaluation of subscription financing must be assessed in a multicomponent strategy including stakeholder interviews, analysis of tender submissions, and tracking utilisation of medicines. Each component underscores a key design of the model and is thus important to track progress against these objectives. Stakeholder interviews with public officials (ministries of health) and pharmaceutical manufacturers will provide a qualitative analysis on effectiveness, and an ad-hoc evaluation for challenges and opportunities. Second, analysing tender bids submitted by manufacturers will provide context for competition and pricing behaviour, specifically, the number of manufacturers which applied for the bid, how competitive 
the process was, and if the tender was fairly awarded to the most competitive bid. Lastly, the incentive for patients is that they face no cost at the point of accessing care. Therefore, it is important to monitor the uptake of medicine use at stages; within the first 3 months, 6 months, 1 year and each successive year to identify the distribution of utilisation and design mechanisms for structuring future agreements.

\section{Challenges}

Benefits of subscription financing include increasing affordability and accessibility of necessary medicines, improving treatment adherence and health, and reducing patient out-of-pocket expenditure on pharmaceuticals - one of the highest attributors to impoverishment globally. However, there are challenges.

New medicines benefit from market exclusivity and monopoly pricing. Awarding a single tender for patented medicines may reduce innovation, R\&D and result in further industry concentration that will reduce competition and price discounts. Import of bioequivalent medicines from external markets and short-term contracts for originators can incentivise future investment and offer solutions to avoid monopolisation as proposed in the Netflix plus amendment. Off-patent markets present different challenges (Mrazek and Mossialos, 2004; Mossialos and Oliver, 2005).

Distribution of generics in LMICs can be problematic for several reasons. Evidence indicates bioequivalence is not a guarantee in all LMICs which can lead to quality, safety and efficacy concerns (Nebot Giralt et al., 2017). Bioequivalence is of greatest concern in these countries because of insufficient regulation for pharmaceuticals compared to high income countries. LMICs lack regulatory and inspection mechanisms at the country or supranational level akin to the FDA and EMA. WHO research estimates $10 \%$ of all medicines in LMICs are substandard or counterfeit, particularly reported in Africa and the Americas (Newton et al., 2010; Mezher, 2017). This has irreversibly damaged the reputation of generics in LMICs, with consumers often selecting to pay out-of-pocket for branded alternatives in fear of medical harm. This effectively reduces competition among producers and limits potential savings for payers and patients. Pricing agreements will not solve this challenge. Governments must introduce strict regulations and penalties for non-compliant generic producers and promote the use of bioequivalent generics where available.

A further limitation requires that payers be able to accurately predict the number of patients likely to engage in treatment to determine a price point. This requires resources and infrastructure not available in most low-income countries. In addition, payment requires substantial capital for licensing fees, likely generated from increased taxes, insurance premiums or diverting funds from other public services and may engender political resistance. Finally, insufficient data - and no data in low-income countries - means pharmaceutical corporations, which wield significant global decision-making power and are generally risk averse, may avoid engagement in highestneed high-risk settings. Despite potential for earning higher profits with subscription financing, return on investment is capped, deterring participation and adversely impacting monopoly producers. The complexity of national infrastructure coupled with big pharma risk aversion pose challenges for competition and pricing and requires further context-specific evidence to accurately inform practice.

\section{Conclusion}

Subscription financing has the potential to reform existing insurance contracts and reduce the imbalance of power in the principal-agent relationship between payers and suppliers. The opioids crisis in the United States has increased rates of hepatitis C, and thus the need for policy and payment reform (Powell et al., 2019). The 'Netflix model' has received attention for its success in combating hepatitis $\mathrm{C}$ and implications for additional chronic and communicable diseases. Due to the confidentiality agreement on Australia's 5-year trial of the subscription model, 
published evidence is lacking. Implementation in Louisiana and Washington DC may help benchmarking in high-income contexts and encourage LMICs to pursue similar financing arrangements with the interest of patients and cost containment.

Author contributions. AC and EM designed the analysis. AC completed the first draft of the paper. EM helped revise the paper. NH provided critical interpretation and revisions. All authors approved the final version for submission.

Conflict of interest. None declared.

\section{References}

Aitken M and Kleinrock M (2015) Global use of medicines in 2020. Available at https://www.iqvia.com/-/media/iqvia/pdfs/ institute-reports/global-medicines-use-in-2020.

American Diabetes Association (2007) Generic drugs. Diabetes Care 30, 173-173. https://doi.org/10.2337/dc07-9918

Atun R, Silva S and Knaul FM (2017) Innovative financing instruments for global health 2002-15: a systematic analysis. The Lancet. Global Health 5, e720-e726. https://doi.org/10.1016/S2214-109X(17)30198-5.

Azzopardi-Muscat N, Schroder-Beck P and Brand H (2017) The European Union joint procurement agreement for crossborder health threats: what is the potential for this new mechanism of health system collaboration? Health Economics, Policy and Law 12, 43-59. https://doi.org/10.1017/S1744133116000219.

Chen T, Fenyo K and Yang S (2018) Thinking inside the subscription box: new research on e-commerce consumers. McKinsey \& Company. Available at https://www.mckinsey.com/industries/high-tech/our-insights/thinking-inside-thesubscription-box-new-research-on-ecommerce-consumers\#0.

Dranitsaris G, Jacobs I, Kirchhoff C, Popovian R and Shane LG (2017) Drug tendering: drug supply and shortage implications for the uptake of biosimilars. ClinicoEconomics and Outcomes Research 9, 573-584. https://doi.org/10.2147/CEOR. S140063.

Espin J, Rovira J, Calleja A, Azzopardi-Muscat N, Richardson E, Palm W and Panteli D (2016) How can voluntary crossborder collaboration in public procurement improve access to health technologies in Europe? Available at http://www.euro. who.int/pubrequest.

European Medicines Agency (2013) Standard operating procedure: Orphan medicinal product designation. Available at http://www.ema.europa.eu/docs/en_GB/document_library/Standard_Operating_Procedure_-_SOP/2009/09/WC500002947. pdf.

Fuller RL and Goldfield N (2016) Paying for on-patent pharmaceuticals. Journal of Ambulatory Care Management 39, 143149. https://doi.org/10.1097/JAC.0000000000000136.

Gagnon M-A and Lexchin J (2008) The cost of pushing pills: a new estimate of pharmaceutical promotion expenditures in the United States. PLoS Medicine 5, e1. https://doi.org/10.1371/journal.pmed.0050001.

Goldman DP, Jena AB, Philipson T and Sun E (2008) Drug licenses: a new model for pharmaceutical pricing. Health Affairs 27, 122-129. https://doi.org/10.1377/hlthaff.27.1.122.

Izaret J-M, Matthews D and Lubkeman M (2019) Aligning economic incentives to eradicate diseases. Available at https:// www.bcg.com/en-gb/publications/2019/aligning-economic-incentives-to-eradicate-diseases.aspx.

Mezher M (2017) WHO: 1 in 10 medicines in developing countries is substandard or fake. Available at https://www.who.int/ news-room/detail/28-11-2017-1-in-10-medical-products-in-developing-countries-is-substandard-or-falsified.

Moon S and Erickson E (2019) Universal medicine access through lump-sum remuneration - Australia's approach to hepatitis C. New England Journal of Medicine 380, 607-610. https://doi.org/10.1056/NEJMp1813728.

Morel CM, McGuire A and Mossialos E (2011) The level of income appears to have no consistent bearing on pharmaceutical prices across countries. Health Affairs 30, 1545-1552. https://doi.org/10.1377/hlthaff.2010.0317.

Mossialos E and Oliver A (2005) An overview of pharmaceutical policy in four countries: France, Germany, the Netherlands and the United Kingdom. International Journal of Health Planning and Management 20, 291-306. https://doi.org/10.1002/ hpm.816.

Mrazek M and Mossialos E (2004) Regulating pharmaceutical prices in the European Union. In Mossialos E, Mrazek M and Walley T (eds), Regulating Pharmaceuticals in Europe. Striving for Efficiency, Equity and Quality. Buckingham: Open University Press, pp. 114-129. Available at http://www.euro.who.int/_data/assets/pdf_file/0008/98432/E83015.pdf.

Nebot Giralt A, Schiavetti B, Meessen B, Pouget C, Caudron JM, Marchal B, Massat P, Thys S and Ravinetto R (2017) Quality assurance of medicines supplied to low-income and middle-income countries: poor products in shiny boxes? BMJ Global Health 2, e000172. https://doi.org/10.1136/bmjgh-2016-000172.

Newton PN, Green MD and Fernández FM (2010) Impact of poor-quality medicines in the 'developing' world. Trends in Pharmacological Sciences 31, 99-101. https://doi.org/10.1016/j.tips.2009.11.005.

Nikoloski Z and Mossialos E (2018) Membership in Seguro popular in Mexico linked to a small reduction in catastrophic health expenditure. Health Affairs 37, 1169-1177. https://doi.org/10.1377/hlthaff.2017.1510. 
PAHO (2015) MERCOSUR countries create a negotiating mechanism to procure high-cost medicines, with PAHO support. Available at http://www.paho.org/hq/index.php?option=com_content\&view=article\&id=11441\%3A2015-mercosur-estadosasociados-concretaron-mecanismo-de-compra-de-medicamentos-de-alto-costo-con-apoyo-ops\&Itemid=1926\&lang=en.

Pan American Health Organization (2017) Strategic fund: annual report 2016. Available at http://www.paho.org.

Perez-Casas C, Herranz E and Ford N (2001) Pricing of drugs and donations: options for sustainable equity pricing. Tropical Medicine and International Health 6, 960-964. https://doi.org/10.1046/j.1365-3156.2001.00801.x.

Philipp W (2017) Joint meeting of CVO/CMO/HSC on influenza preparedness in the context of one health the EU joint procurement mechanism-example of pandemic influenza vaccines. Available at https://ec.europa.eu/food/sites/food/files/ animals/docs/ad_control-measures_hapai_pres07.pdf.

Powell D, Alpert A and Pacula RL (2019) A transitioning epidemic: how the opioid crisis is driving the rise in hepatitis C. Health Affairs (Project Hope) 38, 287-294. https://doi.org/10.1377/hlthaff.2018.05232.

Razmaria AA (2016) Generic drugs. JAMA - Journal of the American Medical Association 315, 2746. https://doi.org/10.1001/ jama.2016.3990.

Sagonowsky E (2019) Louisiana has picked its 'Netflix' hepatitis C partner: Gilead's new generics unit | FiercePharma. FiercePharma. Available at https://www.fiercepharma.com/pharma/louisiana-picks-gilead-subsidiary-to-partner-netflixmodel-for-hep-c-drugs.

Silverman R, Keller JM, Glassman A and Chalkidou K (2019) Tackling the triple transition in global health procurement: final report of CGD's working group on the future of global health procurement. Available at https://www.cgdev.org/sites/ default/files/better-health-procurement-tackling-triple-transition.pdf.

Smith RD, Correa C and Oh C (2009) Trade, TRIPS, and pharmaceuticals. Lancet (London, England) 373, 684-691. https:// doi.org/10.1016/S0140-6736(08)61779-1.

Sood N, Ung D, Shankar A and Strom BL (2018) A novel strategy for increasing access to treatment for hepatitis C virus infection for Medicaid beneficiaries. Annals of Internal Medicine 169, 118. https://doi.org/10.7326/M18-0186.

Thomson S, Foubiser T and Mossialos E (2010) Can user charges make health care more efficient? BMJ 341, 487-489. https://doi.org/10.1136/bmj.c3759.

Trusheim MR, Cassidy WM and Bach PB (2018) Alternative state-level financing for hepatitis C treatment - the 'Netflix Model'. JAMA 320 : 1977. https://doi.org/10.1001/jama.2018.15782.

US Food and Drug Administration (2017) Developing products for rare diseases. Office of the commissioner. https://doi. org/10.4137/EHI.S24583.

WHO (2007) Multi-country regional pooled procurement of medicines. Identifying key principles for enabling regional pooled procurement and a framework for inter-regional collaboration in the African, Caribbean and Pacific Island Countries. Available at http://www.who.int/medicines/publications/PooledProcurement.pdf.

WHO | Country and Regional Data on Diabetes. (2011) WHO. Available at https://www.who.int/diabetes/facts/world_figures/en/index5.html.

Zhang A, Nikoloski Z and Mossialos E (2017) Does health insurance reduce out-of-pocket expenditure? Heterogeneity among China's middle-aged and elderly. Social Science \& Medicine 190, 11-19. https://doi.org/10.1016/J.SOCSCIMED. 2017.08.005.

Cite this article: Cherla A, Howard N, Mossialos E (2021). The 'Netflix plus model': can subscription financing improve access to medicines in low- and middle-income countries? Health Economics, Policy and Law 16, 113-123. https:// doi.org/10.1017/S1744133120000031 